Title:

RADIANS: A Multidisciplinary Central Nervous System Clinic Model For Radiation Oncology and Neurosurgery Practice

Authors:

Shearwood McClelland III MD ${ }^{1,2}$, Timur Mitin MD PhD², Jerry J Jaboin MD PhD², Jeremy N Ciporen $\mathrm{MD}^{3}$

Institutions:

${ }^{1}$ Department of Radiation Oncology, Indiana University School of Medicine, Indianapolis, IN; ${ }^{2}$ Department of Radiation Medicine, Oregon Health and Science University, Portland, OR; ${ }^{3}$ Department of Neurological Surgery, Oregon Health and Science University, Portland, OR

Keywords:

Radiation Oncology, Neurosurgery, Central Nervous System Metastases, Multidisciplinary Clinic, RADIANS, Community Hospital

Conflict of Interests: Dr. Mitin receives research funding from Novocure. No other authors have any conflicts of interest.

Acknowledgments: The authors would like to thank Diane Ingram for invaluable assistance.

Corresponding Author:

Shearwood McClelland III, MD

Department of Radiation Medicine, Indiana University School of Medicine

535 Barnhill Drive, RT 041

Indianapolis, IN 46202

Phone: $503-681-4200$

Fax: 503-681-4210

Email: drwood@post.harvard.edu

This is the author's manuscript of the article published in final edited form as: 


\title{
RADIANS: A Multidisciplinary Central Nervous System Clinic Model For Radiation Oncology and Neurosurgery Practice
}

\begin{abstract}
INTRODUCTION: Radiation therapy for central nervous system (CNS) disease commonly involves collaboration between Radiation Oncology and Neurosurgery. We describe our early experience with a multidisciplinary clinic model.
\end{abstract}

METHODS: In 2016, the novel RADIANS (RADlation oncology And NeuroSurgery) clinic model was initiated at a community hospital. Disease and treatment demographics were collected and analyzed. Patient satisfaction was assessed via blinded survey questionnaire.

RESULTS: Forty-two patients have been seen since RADIANS inception. Median age was 65; median patient distance from RADIANS was 42.7 miles (mean=62.6; range=0.7-285). Half of patients travelled $>50$ miles to receive care; $>80 \%$ were seen for CNS metastases. Of patients receiving radiation, $75 \%$ received stereotactic radiosurgery (SRS)/SBRT. Mean overall satisfaction from 0 (not satisfied) to 5 (very satisfied) was 4.8.

CONCLUSIONS: The RADIANS clinic model has proved viable and well-liked by patients in a community setting, with the majority of radiation therapy administered being SRS/SBRT rather than conventional fractionation. 


\section{Introduction}

Optimal management of central nervous system (CNS) cancer can only be achieved when neurosurgeons and radiation oncologists collaborate to determine the best selection/sequence of the most cuttingedge treatment modalities. This collaborative effort is most prominently witnessed clinically during frame-based stereotactic radiation, where both disciplines work hand-in-hand from frame placement to the conclusion of treatment delivery to optimize patient care (1). However, such partnership needs to start at the first meeting when treatment options are presented to the patient and the treatment algorithm is fashioned. Unlike multidisciplinary clinic models implemented for cancer of other organ systems (in tandem with surgery and medical oncology), models where patients are seen in the same room at the same time by both neurosurgeons and radiation oncologists have been lacking, especially outside of large academic institutions (2-4).

\section{Material and Methods}

At our institution, we built the novel RADIANS (RADlation oncology And NeuroSurgery) clinic model in August 2016 at a community satellite location. After receiving approval from the Institutional Review Board, we collected and analyzed disease and treatment demographics for each patient. Patient satisfaction was assessed via survey questionnaire, where both radiation oncology and neurosurgery physicians were blinded to both the administration of and patient responses in surveys.

\section{Results}

Forty-two RADIANS patients have been evaluated in the multidisciplinary single-visit clinic since its inception, with $76 \%$ presenting with metastatic disease (Table 1). Median patient age was 65 years, median patient distance to clinic was 42.7 miles; half traveled $>50$ miles for consultation. Of patients receiving radiation, the majority (75\%) received stereotactic radiosurgery/body radiotherapy. Survey 
responses revealed that $92 \%$ found that having a consultation with two physicians at the same time in the same room "was a totally new experience". All responders found that having two physicians at the same time was "a better way to be evaluated than simply having two separate appointments with these two physicians", while describing the dynamics of the evaluation process as being shared equally between the radiation oncologist and neurosurgeon. Half of responders felt comfortable with receiving two separate bills rather than a single bill for their RADIANS visit, and all responders would recommend RADIANS for a friend or relative with a newly diagnosed spine or brain tumor. The average overall satisfaction on a 0 (not satisfied) to 5 (very satisfied) scale was 4.8 .

\section{Discussion}

The RADIANS model has improved patient access to timely state-of-the-art multidisciplinary care, proving greatly needed and well-received by patients with complex CNS diagnoses, where decisionmaking regarding the risks/benefits of neurosurgical interventions and radiation therapy approaches can be made between both disciplines in a single setting and expediently conveyed to the patient. It has also proved useful for benign intracranial disease, allowing evidence-based collaboration to occur regarding situations where the risks may outweigh the benefits of radiation (5). Through RADIANS we are also treating patients with glioblastoma with novel alternating electric field therapy (6). From an inpatient perspective, patients seen by neurosurgery lacking urgent pathology can be monitored as outpatients knowing their care will be streamlined at the next RADIANS clinic, rather than undergo a costly admission/lengthening of hospitalization awaiting inpatient radiation oncology consultation.

Our preliminary results indicate that the RADIANS clinic model is viable in a community setting and popular with patients. Over time, we hope it will expand to other community oncology centers and become a nidus for clinical research through investigator-initiated and cooperative group clinical trials. 
Continued collection and analysis of treatment outcomes and patient experiences will remain a focus of the RADIANS clinic to determine the best utilization of resources for treating CNS malignancies.

\section{References}

1. Lunsford LD, Flickinger JC, Steiner L. The gamma knife. JAMA. 1988;259:2544.

2. Aizer AA, Paly JJ, Zietman AL, et al. Multidisciplinary care and pursuit of active surveillance in low-risk prostate cancer. J Clin Oncol. 2012;30:3071-3076.

3. Harper JL, De Costa AM, Garrett-Mayer E, Sterba KR. Incorporating patient satisfaction metrics in assessing multidisciplinary breast cancer care quality. South Med J. 2015;108:372-376.

4. Abou-Jaoude PM, Zeitouni AG, Soualmi L, Leblanc R. Multimodal multidisciplinary surgical approach for the treatment of pituitary tumours. J Otolaryngol. 2007;36:322-326.

5. McClelland $\mathrm{S} 3^{\text {rd }}$, Mitin $\mathrm{T}$, Ciporen $\mathrm{JN}$. Is radiation therapy for subtotally resected meningioma causing more harm than good? Int J Radiat Oncol Biol Phys. 2018;100:803-804.

6. Halasz LM, Mitin T. Tumor-treating fields: answering the concern about quality of life. JAMA Oncol. 2018;4:504-505. 
Table 1: Distribution of RADIANS clinic patients

( ${ }^{*}$ Two patients had brain and spine metastases; ${ }^{* *}$ Two patients received SBRT and subsequently required WBRT at a later date)

\begin{tabular}{|c|c|}
\hline Patient Demographics & \\
\hline Mean age (years) & 62.9 \\
\hline Median age (years) & 65.0 \\
\hline \multicolumn{2}{|l|}{ Distance from RADIANS (miles) } \\
\hline Mean & 62.6 \\
\hline Median & 42.7 \\
\hline $0-10$ miles & $33.3 \%$ \\
\hline $11-20$ miles & $9.5 \%$ \\
\hline 21-50 miles & $7.1 \%$ \\
\hline 51-100 miles & $35.7 \%$ \\
\hline $101-200$ miles & $4.8 \%$ \\
\hline $201+$ miles & $9.5 \%$ \\
\hline Disease Demographics & $\mathbf{N}$ \\
\hline Brain metastases & 16 \\
\hline Spine metastases & $18^{*}$ \\
\hline Malignant primary brain tumors & 3 \\
\hline Non-malignant primary brain tumors & 3 \\
\hline Cavernoma & 1 \\
\hline Primary spine tumors & 3 \\
\hline \multicolumn{2}{|l|}{ 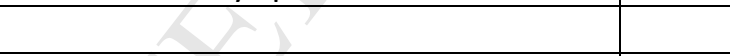 } \\
\hline Treatment Modality & $\mathbf{N}$ \\
\hline Surgery with radiation & 14 \\
\hline Radiation without surgery & 12 \\
\hline Surgery without radiation & 5 \\
\hline No surgery or radiation & 11 \\
\hline \multicolumn{2}{|l|}{ 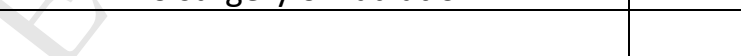 } \\
\hline Radiation Treatment Received & $\mathbf{N}$ \\
\hline Stereotactic radiosurgery/SBRT** & 21 \\
\hline Conventionally fractionated RT & 7 \\
\hline None & 16 \\
\hline
\end{tabular}




\section{Abbreviations}

CNS $=$ Central nervous system

SRS $=$ Stereotactic radiosurgery

SBRT = Stereotactic body radiation therapy

RADIANS = RADlation oncology And NeuroSurgery 